\title{
Correction to: Enhancing SVM for survival data using local invariances and weighting
}

Hector Sanz ${ }^{1 *}$, Ferran Reverter ${ }^{1,2}$ and Clarissa Valim ${ }^{3,4}$

The original article can be found online at https://doi.org/10.1186/ s12859-020-3481-2.

*Correspondence: hsrodenas@ gmail.com

${ }^{1}$ Department of Genetics,

Microbiology and Statistics, Faculty of Biology, Universitat de Barcelona, Diagonal, 643, 08028 Barcelona, Catalonia, Spain

Full list of author information is available at the end of the article

\section{Correction to: BMC Bioinformatics 21, 193 (2020)}

https://doi.org/10.1186/s12859-020-3481-2

Following publication of the original article [1], the authors identified errors in the equations. The correct equations are given below.

Equation (7)

$S^{z(t i)}=\frac{S^{(t i+z)}}{S^{(i)}}$

Equation (8)

$$
\underset{\boldsymbol{w}, \boldsymbol{w}^{*}, b, b^{*}}{\operatorname{minimize}} \frac{1}{2}\left(\|\boldsymbol{w}\|^{2}+\gamma\left\|\boldsymbol{w}^{*}\right\|^{2}\right)+C \sum_{i=1}^{n} \xi_{i}
$$

subject to $\xi_{i}=\left(\left\langle\boldsymbol{w}^{*}, \boldsymbol{x}_{i}^{*}\right\rangle+b^{*}\right)$,

$$
\begin{aligned}
& i=1, \ldots, n \\
& i=1, \ldots, n \\
& i=1, \ldots, n
\end{aligned}
$$$$
y_{i}\left(\left\langle\boldsymbol{w}, \boldsymbol{x}_{i}\right\rangle+b\right) \geq 1-\left(\left\langle\boldsymbol{w}^{*}, \boldsymbol{x}_{i}^{*}\right\rangle+b^{*}\right),
$$$$
\left(\left\langle\boldsymbol{w}^{*}, \boldsymbol{x}_{i}^{*}\right\rangle+b^{*}\right) \geq 0,
$$

Equation (10)

$$
\begin{array}{rll}
\underset{\boldsymbol{w}, b}{\operatorname{minimize}} & \frac{1}{2}\|\boldsymbol{w}\|^{2} & \\
\text { subject to } & y_{i}\left(\left\langle\boldsymbol{w}, \boldsymbol{x}_{i}\right\rangle=b\right) \geq 1, & i=1, \ldots, n \\
& z_{i}^{-} \leq\left\langle\boldsymbol{w}, \boldsymbol{x}_{i}\right\rangle+b \leq z_{i}^{+}, & i=n+1, \ldots, m
\end{array}
$$

Re-expression of Equation (10)

$$
\begin{aligned}
& \underset{\boldsymbol{w}, \xi, \xi^{-}, \xi^{+}, b}{\operatorname{minimize}} \quad \frac{1}{2}\|\boldsymbol{w}\|^{2}+C \sum_{i=1}^{n} \xi_{i}+\tilde{C} \sum_{i=n+1}^{m}\left(\xi_{i}^{-}+\xi_{i}^{+}\right) \\
& \text {subject to } y_{i}\left(\left\langle\boldsymbol{w}, \boldsymbol{x}_{i}\right\rangle+b\right) \geq 1-\xi_{i}, \quad i=1, \ldots, n \\
& z_{i}^{-}-\xi_{i}^{-} \leq\left\langle\boldsymbol{w}, \boldsymbol{x}_{i}\right\rangle+b \leq z_{i}^{+}+\xi_{i}^{+}, \quad i=n+1, \ldots, m \\
& \xi_{i} \geq 0, \quad i=1, \ldots, n \\
& \xi_{i}^{-} \geq 0, \quad i=n+1, \ldots, m \\
& \xi_{i}^{+} \geq 0, \quad i=n+1, \ldots, m
\end{aligned}
$$

(-) The Author(s). 2020 Open Access This article is licensed under a Creative Commons Attribution 4.0 International License, which permits use, sharing, adaptation, distribution and reproduction in any medium or format, as long as you give appropriate credit to the original author(s) and the source, provide a link to the Creative Commons licence, and indicate if changes were made. The images or other third party material in this article are included in the article's Creative Commons licence, unless indicated otherwise in a credit line to the material. If material is not included in the article's Creative Commons licence and your intended use is not permitted by statutory regulation or exceeds the permitted use, you will need to obtain permission directly from the copyright holder. To view a copy of this licence, visit http://creativecommons.org/licenses/by/4.0/. The Creative Commons Public Domain Dedication waiver (http://creativecommons.org/publicdomain/zero/1.0/) applies to the data made available in this article, unless otherwise stated in a credit line to the data. 
Equation (11)

$$
\underset{\boldsymbol{w}, b}{\operatorname{minimize}} \frac{1}{2}\|\boldsymbol{w}\|^{2}
$$

subject to $y_{i}\left(\left\langle\boldsymbol{w}, \boldsymbol{x}_{i}\right\rangle+b\right) \geq 1$,

$$
\begin{aligned}
& i=1, \ldots, n \\
& i=n+1, \ldots, m
\end{aligned}
$$$$
z_{i}^{-} \leq\left\langle\boldsymbol{w}, \boldsymbol{x}_{i}\right\rangle+b \leq z_{i}^{+},
$$

\title{
Equation (13)
}

$$
\begin{array}{cll}
\underset{\boldsymbol{w}, \boldsymbol{\xi}}{\operatorname{minimize}} & \frac{1}{2}\|\boldsymbol{w}\|^{2}+C \sum_{i=1}^{n} W_{i} \xi_{i} & \\
\text { subject to } & y_{i}\left(\left\langle\boldsymbol{w}, \boldsymbol{x}_{i}\right\rangle+b\right) \geq 1-\xi_{i}, & i=1, \ldots, n \\
& \xi_{i} \geq 0, & i=1, \ldots, n
\end{array}
$$

\section{Equation (16)}

$$
z_{x_{i, j}}(\boldsymbol{x})=\frac{1}{\sigma^{2}}\left(x^{j}-x_{i}^{j}\right) \exp \left(-\frac{1}{2 \sigma^{2}}\left\|\boldsymbol{x}=\boldsymbol{x}_{i}\right\|^{2}\right)
$$

The original article has been corrected.

\begin{abstract}
Author details
1Department of Genetics, Microbiology and Statistics, Faculty of Biology, Universitat de Barcelona, Diagonal, 643, 08028 Barcelona, Catalonia, Spain. ${ }^{2}$ Centre for Genomic Regulation (CRG), The Barcelona Institute for Science and Technology, Dr. Aiguader 88, 08003 Barcelona, Spain. ${ }^{3}$ Department of Global Health, Boston University, 801 Massachusetts Avenue, Boston, MA 02118, USA. ${ }^{4}$ Department of Immunology and Infectious Diseases, Harvard T.H. Chen School of Public Health, 675 Huntington Ave, Boston, MA 02115, USA.
\end{abstract}

Published online: 27 August 2020

Reference

1. Sanz, et al. Enhancing SVM for survival data using local invariances and weighting. BMC Bioinformatics. 2020;21:193. https://doi.org/10.1186/s12859-020-3481-2. 